\title{
The 6/24 rule: A review and proposal for an international standard of a minimum of six hours of continuous sleep in detention settings
}

\author{
Pau Pérez-Sales*
}

\section{Introduction}

Sleep deprivation is one of the most prevalent and widely used methods of psychological torture. Its effects on the body are without direct physical aggression and include significant somatic and psychological impacts and suffering. It is used in multiple coercive environments as a way, among other purposes, of degradation, debilitation, punishment both before and during the interrogation of detainees. In this specific context, it produces cognitive, emotional and physical exhaustion, with the aim of obtaining submission or compliance, and ultimately information or confession (Pérez-Sales, 2017; Reynolds \& Banks, 2010; Sveaass, 2008).

There is no universally accepted legal definition of what should be considered sleep deprivation in the context of torture. There are however converging positions from the legal and jurisprudential, and especially medical and psychiatric fields that allow for establishing sufficiently clear recommendations for the international community to take a reasoned stance. Within the framework of torture as defined in the United Nations Convention (UNCAT), we propose that intentionally forcing a person to have less than 6 hours of continuous, restful sleep must be considered a form of degrading treatment that could amount to cruel and inhuman treatment. We also suggest that when this daily sleep deprivation is intentionally prolonged in a sustained manner for three days or more, it should be considered as a form of torture in itself, irrespective of other coexisting or cumulative elements that may aggravate the condition.

Our proposal and position will be justified with due regard to available knowledge.

\section{Background}

Epidemiological and public health studies demonstrate a slight variability in individual needs of sleep: from 6 to 8 hours on average for adults, depending on age. An International Consensus promoted by the US National Sleep Foundation (Hirshkowitz et al., 2015; Watson, Badr, Belenk, \& Bliwise, 2015) agreed that a healthy normal sleep pattern for an adult should include a minimum of $7(+/-1)$ hours of daily continuous sleep ${ }^{1}$ (see table 1 ). A number of

Regarding adults and older adults, metaanalyses show there is a significant difference in the distribution of Stage 1, 2 (increase) and REM (decrease), but this is only detectable in Actigraphic studies (Ohayon et al., 2004). 
reviews and meta-analyses of international cohort and longitudinal studies have also consistently shown that mortality is significantly increased in persons sleeping less than 6 (Åkerstedt et al., 2017) to 7 hours per day (Cappuccio, D'Elia, Strazzullo, \& Miller, 2010; Yin, J., Jin, X., Shan, Z., Li, S., Huang, H., Li, P. \& Liu, L, 2017). This is due to both metabolic changes that increase the risk of death-related diseases (Trivedi, Holger, Bui, Craddock, \& Tartar, 2017) and a significantly higher rate of suicide in the affected persons (Pereira, Martins, \& Fernandes, 2017). In their international study of reference to date on normal patterns of sleep across a lifespan, Ohayon, Carskadon, Guilleminault, \& Vitiello (2004) developed a comprehensive meta-analysis based on 65 studies, which found that sleep duration only slightly decreased around one hour from adult to old age in healthy individuals. Additionally, reviews of the reported average time of normal duration of sleep across countries and cultures, including data from pre-industrial societies, provide similar results. Analogous results are obtained in historical studies that compare duration of normal sleep patterns from decade to decade since such records were available (Hoyos, Glozier, \& Marshall, 2015; Simonelli et al., 2018; Yetish et al., 2015).

The richness of this data demonstrates that for an adult (18-65 yrs), the minimum duration of necessary sleep is no less than

Table 1: International Consensus on Normal Sleep Pattern (Hirshkowitz et al., 2015; Watson et al., 2015).

\begin{tabular}{|c|c|c|c|}
\hline Age & Recommended, $h$ & May be appropriate, $h$ & Not recommended, $h$ \\
\hline $\begin{array}{l}\text { Newborns } \\
0-3 \text { mo }\end{array}$ & 14 to 17 & $\begin{array}{l}11 \text { to } 13 \\
18 \text { to } 19\end{array}$ & $\begin{array}{l}\text { Less than } 11 \\
\text { More than } 19\end{array}$ \\
\hline $\begin{array}{l}\text { Infants } \\
4-11 \mathrm{mo}\end{array}$ & 12 to 15 & $\begin{array}{l}10 \text { to } 11 \\
16 \text { to } 18\end{array}$ & $\begin{array}{l}\text { Less than } 10 \\
\text { More than } 18\end{array}$ \\
\hline $\begin{array}{l}\text { Toddlers } \\
1-2 \mathrm{y}\end{array}$ & 11 to 14 & $\begin{array}{l}9 \text { to } 10 \\
15 \text { to } 16\end{array}$ & $\begin{array}{l}\text { Less than } 9 \\
\text { More than } 16\end{array}$ \\
\hline $\begin{array}{l}\text { Prescholers } \\
3-5 \mathrm{y}\end{array}$ & 10 to 13 & $\begin{array}{l}8 \text { to } 9 \\
14\end{array}$ & $\begin{array}{l}\text { Less than } 8 \\
\text { More than } 14\end{array}$ \\
\hline $\begin{array}{l}\text { School-aged } \\
\text { children } \\
6-13 y\end{array}$ & 9 to 11 & $\begin{array}{l}7 \text { to } 8 \\
12\end{array}$ & $\begin{array}{l}\text { Less than } 7 \\
\text { More than } 12\end{array}$ \\
\hline $\begin{array}{l}\text { Teenagers } \\
14-17 \mathrm{y}\end{array}$ & 8 to 10 & $\begin{array}{l}7 \\
11\end{array}$ & $\begin{array}{l}\text { Less than } 7 \\
\text { More than } 11\end{array}$ \\
\hline $\begin{array}{l}\text { Young adults } \\
18-25 \mathrm{y}\end{array}$ & 7 to 9 & $\begin{array}{l}6 \\
10 \text { to } 11\end{array}$ & $\begin{array}{l}\text { Less than } 6 \\
\text { More than } 11\end{array}$ \\
\hline $\begin{array}{l}\text { Adults } \\
26-64 \text { y }\end{array}$ & 7 to 9 & $\begin{array}{l}6 \\
10\end{array}$ & $\begin{array}{l}\text { Less than } 6 \\
\text { More than } 10\end{array}$ \\
\hline $\begin{array}{l}\text { Older adults } \\
\geq 65 \mathrm{y}\end{array}$ & 7 to 8 & $\begin{array}{l}5 \text { to } 6 \\
9\end{array}$ & $\begin{array}{l}\text { Less than } 5 \\
\text { More than } 9\end{array}$ \\
\hline
\end{tabular}


6 hours and for older adults $(>65)$ not less than 5 hours. The minimum duration for young adults and children is higher.

Table 2 collects selected impacts of sleep deprivation in the course of coercive interrogations, ill-treatment and torture, with key references selected among the many available. It shows how sleep deprivation affects some of the most essential cognitive and emotional functions of the brain.

Each of these effects can be traced neurologically. More than a decade ago, pioneering military studies in the USA using small samples, employing magnetic resonance imaging (fMRI) had already shown that after just 24 hours of sleeplessness there was clear vulnerability of integrated decision-making to sleeplessness that was accompanied by a breakdown in task-specific neural activity in prefrontal cortex that correlated with behavioural performance (Schnyer, Zeithamova, \& Williams, 2009).

In a pioneering controlled study, Dai et alt (2019) found using Functional Magnetic Resonance Imaging (fMRI), that prolonged acute sleep deprivation (lasting
$20,24,32$ or $36 \mathrm{~h}$ ) exhibits accumulative brain atrophic effects which may provide the neurobiological basis for attention and memory impairments following sleep loss. Using a similar neuroimaging test, Chen et al. (2018) and Kong et al. (2018), found that the amplitude of low-frequency fluctuation and short-range and long-range functional connectivity density in four specific areas of the brain may be potential biomarkers of acute sleep deprivation with high discriminating value.

All these studies open the door in the future to potential detection and recognition of signals of the use of sleep deprivation as torture, as well as its impacts. It also provides a potential tool supporting the forensic analysis of credibility of allegations of sleep deprivation (SD).

These short term impacts and their neurobiological correlates are no surprise. More than fifty years ago, the CIA torture handbook, known as the KUBARK manual, warned against an excessive use of sleep deprivation: "any attempt to produce compliant behaviour by procedures which produce...

Table 2: Impairments produced by sleep deprivation relevant to coercive interrogation, ill-treatment and torture.

- Memory retrieval (Havekes \& Abel, 2017)

- Memory accuracy (Blagrove \& Akehurst, 2000)

- Cognitive functioning and reasoning (Killgore, 2010; Lim \& Dinges, 2010)

- Emotion recognition (Killgore, Balkin, Yarnell, \& Capaldi, 2017)

- Emotional reactions (Fairholme \& Manber, 2015; Tempesta et al., 2010)

- Moral judgment (Barnes, Gunia, \& Wagner, 2015; Killgore et al., 2007; Tempesta et al., 2012)

- Threat analysis (Goldstein-Piekarski, Greer, Saletin, \& Walker, 2015),

- Decision-making process and risk analysis (Horne \& Harrison, 2000; McKenna, Dickinson, \& Orff, 2007).
Only one night of sleep deprivation:

- Increases suggestibility and is sufficient to produce statistically significant differences in the number of false confessions during interrogation (Blagrove, 1996; Blagrove \& Akehurst, 2000).

- Increases the number of false memories recalled(Frenda, Patihis, Loftus, Lewis, \& Fenn, 2014).

- Amplifies the effects of physical pain (Lautenbacher, Kundermann, \& Krieg, 2006; Schrimpf et al., 2015)

- Increases fear-memory consolidation and post-traumatic stress symptoms (Feng, Becker, Zheng, \& Feng, 2018). 
disturbances of homeostasis, fatigue, sleep deprivation, isolation, discomfort, or disturbing emotional states carries with it the hazard of producing inaccuracy and unreliability" (p. 88).

\section{Sleep deprivation and mental and physical suffering}

Some authors have previously proposed the existence of an antidepressant effect following 24 hours of sleep deprivation. Subsequent studies have shown that the effect is deleterious and of no clinical use (Boland et al., 2017). On the contrary, sleep deprivation has consistently been shown to exacerbate symptoms of mania (Krystal, 2012). A recent meta-analysis has provided strong evidence that insomnia is a significant predictor for the onset of depression (10 studies), anxiety (six studies), alcohol abuse (two studies) and psychosis (one study) (Hertenstein et al., 2019). A review of studies using poly-somnographic methods was also conclusive in showing that sleep continuity disturbances imply a trans-diagnostic imbalance in the arousal system, likely representing a basic dimension of mental health. Sleep depth and REM variables play a key role in psychiatric comorbidity processes and increase symptoms of affective disorders, anxiety disorders, eating disorders, borderline and antisocial personality disorders, attentiondeficit-hyperactivity disorder (ADHD), and schizophrenia (Baglioni et al., 2016). Moreover sleep deprivation increases and amplifies the perception and effects of physical pain (Lautenbacher et al., 2006). Sleep deprivation, therefore, produces severe physical and emotional suffering.

Military and police regulations. Some military regulations in the past have established lower thresholds. The idea behind this is that interrogation is not a "healthy" situation and a certain level of discomfort due to normal routine procedures must be expected. For instance, based on this reasoning, US Army Manuals during the Bush administration established a threshold of 4 hours of continuous sleep every 24 hours for up to 30 days (US Army, 2006). ${ }^{2,3}$ The medical evidence shown above raises questions regarding such practice, clearly showing that this constituted torture. ${ }^{4}$ Notably, this should be considered along with the American Central Intelligence (CIA) guidelines from a similar date, that stated that all detainees should have eight hours of uninterrupted sleep, ${ }^{5,6}$ a level much higher than the one proposed here.

\section{The first 72 hours}

The medical and psychiatric research reviewed shows unequivocally that the damaging effects of sleep deprivation and its impact in terms of suffering and impairment, in addition to its consequences

FM 2-22.3, supra note 90, at M-30.

3 This has also been contested from within the US Military, as some high rank officers have publicly declared that even if it was useful, which is not evident, this threshold violates the Geneva Conventions (Bolgiano, 2010).

4 The idea that a person can sleep 4 hours or less a day in a prolonged manner cannot be justified by normal procedure. Medical research shows that there is a high level of suffering, a significant damage to the person and a high risk of false confessions. The person is simply not fit for interrogation.

5 Memorandum from Steven G. Bradbury, Principal Deputy Assistant Attorney General, for John A. Rizzo, Senior Deputy General Counsel, Central Intelligence Agency (10 May 2005): FN 36. 30.

6 The FBI's new role, institutionalised under the High Value Interrogation Group (HIG), still permits manipulation of environments, prolonged isolation, and sleep deprivation, although the number of hours a detainee is allowed to sleep is not in the public domain (Greenberg, 2015). 
in terms of lack of reliability of interrogations, are significant at the 24-hour mark. In the early and seminal review that provided the foundation for the CIA Kubark Manual, Albert Biderman and Herbert Zimmer (1961) had already established this 24-hour criterion. Furthermore, "after fortyeight hours without sleep, some people become disorganized and ineffective, whereas some others have still been known to go with their functions largely intact", but "most people deteriorate markedly after about seventy-two hours without sleep, and all deteriorate sooner or later" (p. 44 and seq). They went further to say that "the effects [of sleep deprivation] are intrinsically adverse, and the reaction of the individual is a factor only in determining how long these effects can be withstood" (p. 49). Other authors have also suggested that 24 hours of sleep deprivation affects most individuals, with 72 hours as a definite limit for most human beings (Horne \& Pettitt, 1985; Mikulincer, Babkoff, Caspy, \& Sing, 1989).

Furthermore, SERE training, designed for military surviving in extreme torturous conditions, permits soldiers $48 \mathrm{~h}$ maximum of sleep deprivation (Intelligence Science Board, 2009).

Regarding recovery, a recent international multi-collaborative study demonstrated the need for a minimum of 14 hours of continuous sleep to recover to a normal neurophysiological sleep pattern following $58 \mathrm{~h}$ of sleep deprivation (Hennecke et al., 2019). If this does not occur, the damage increases proportionally.

Overall, we can conclude that available medical studies provide strong grounding to the thesis that 3 days of continuous sleep deprivation is the limit for considering $\mathrm{SD}$ as torture in itself, irrespective of other external factors.

\section{Sleep disruption}

The emphasis on the number of hours of continuous sleep should not obfuscate the relevance of sleep disruption to the thesis proposed. Indeed, the Kubark Manual recommended sleep disruption as more effective than absolute sleep deprivation: "Another objection to the deliberate inducing of debility is that prolonged exertion, loss of sleep, etc., themselves become patterns to which the subject adjusts through apathy. The interrogator should use his power over the resistant subject's physical environment to disrupt patterns of response, not to create them. Meals and sleep granted irregularly, in more than abundance or less than adequacy, the shifts occurring on no discernible time pattern, will normally disorient an interrogate and sap his will to resist more effectively than a sustained deprivation leading to debility" (pp. 92-93).

Sleep disruption in detention settings can be caused, intentionally or not, by multiple factors: hunger, thirst, high and low temperature, noise or sounds, isolation, overcrowding, or by routine or arbitrary practices; roll call, cell search, shouting at the detainee. Additionally, threats and other fear-inducing practices produce dread and anxiety that can induce disrupted sleep. The effects of sleep disruption are to be added to those of sleep deprivation.

A prospective study by Liu et al. (2019) on sleep disruption analysed the impact of awakening experimental subjects with a phone call every hour during a single night. The impact on the participants was dependant on the subject's age: there were statistically significant changes in mood in young people and a decline in memory in older adults. Furthermore, a recent review has suggested that there is a relationship between sleep disruption and aggression through three converging effects: anger, perceived hostility and lowered inhibition 
(Krizan \& Herlache, 2016). These effects depend on disruptions and are independent of the total number of hours in bed. In other words, disrupting sleep has independent cognitive and emotional effects that add to the effects of sleep deprivation.

\section{False confessions-linking length of interrogation and sleep deprivation}

The combined effects of sleep deprivation and the physical, cognitive and emotional effects presented until this point, have been shown to produce an increased number of false confessions. This is due to increased suggestibility (Gudjonsson, 2003; Gudjonsson et al., 2016), weakness associated to physical or psychological deprivations during interrogation and the desire to put an end to the interrogation due to the prolonged suffering it entails.

Length of interrogation. The European Committee on the Prevention of Torture and Inhuman or Degrading Treatment or Punishment (CPT) Standards state that interrogations should be avoided for lengthy periods. However, their recommendations are not concrete (Morgan \& Evans, 2001). The US Supreme Court prescribes the "totalityof-the-circumstances" test. Relevant factors in this test may include the application of physical abuse or psychological coercion; the time, length, circumstances, and place of the interrogation, and the age and education of the detainee, along with other considerations.

Average length of a police interview. Across various epidemiological studies on the self-reported duration of interrogation of suspects by the police, the average duration is found to be between 1 and 2 hours (Baldwin, 1993; Kassin et al., 2007). During a naturalistic study with real interrogations in juveniles, Feld (2013) found that the average interview lasted between 30 and 45 minutes. Experimental studies have consistently shown a direct correlation between false confessions and length of interrogation (Madon, Yang, Smalarz, Guyll, \& Scherr, 2013) with maximum risk of false confession for interrogations lasting 6 hours in length. The study detected interrogations sometimes lasting even up to 16 hours (Drizin \& Leo, 2004). This data combined has led different authors to propose a maximum duration of interrogation of 2 to 4 hours, and up to 6 hours in special circumstances (Davis \& Leo, 2012). Any duration of interrogation longer than 6 hours would be considered coercive, even when brief periods of rest or refreshment are provided.

\section{Legal aspects}

There is, at present, no international regulation providing clear guidance regarding sleep deprivation. This issue of Torture Journal includes a review on the topic by Ergün Cakal. He has summarized the legal framework of sleep deprivation on the basis of the jurisprudence of international tribunals to show that there is ample documentation of cases considering sleep deprivation as a form of cruel, inhuman or degrading treatment, or torture. Of particular note, in what seems the clearest indication of a length of time rule is the case of Sadretdinov v. Russia, in which the European Court of Human Rights, despite no violation being found in that case, found that a minimum of six hours of sleep per night was required before Article 3 of the Convention was breached.” (\$96). ${ }^{7}$

\section{Conclusion}

Epidemiological and public health studies show, across countries and cultures, that an adult needs a minimum of $7(+/-1)$ hours of

ECHR. (2016). Sadretdinov v. Russia, 17564/06. 
sleep per day. In other words, the minimum duration of necessary sleep is no less than 6 hours. The available jurisprudence also seems to point to a 6 hour minimum for considering sleep deprivation. Anything less than this amount produces impairments in memory retrieval and accuracy, cognitive functioning, emotional recognitions and reactions, moral judgment and threat analysis among others. This, in turn, produces a breakdown in the person that will favour false confessions. Additionally, sleep deprivation leads to physical and psychological suffering sometimes of extraordinary severity. Sleep disruption gives rise to similar effects and ultimately potentiates the effects of sleep deprivation. These effects both appear and can be detected during the first 24 hours in most subjects but are present in all subjects after 3 days (72 hours) of partial or continuous sleep deprivation.

As a mnemonic rule, this can be labelled as the $6 / 24 \times 3$ rule.

Those who oppose establishing regulations that can assist both policymakers and the judiciary argue that some level of sleep restriction is acceptable as part of normal detention procedures. Of course, this is true. Although solitary confinement is an unhealthy situation in itself, the Nelson Mandela Rules and the UN Special Rapporteur on torture recommendations, among others, establish a threshold of 15 days as the limit between suffering incidental to legally admissible solitary confinement and torture (Mendez, 2011). It is prolonged solitary confinement that is considered as amounting to torture in itself, irrespective of other cumulative elements. Similar reasoning should be applied to sleep deprivation.

In this issue, Torture Journal offers a collection of papers on the topic. Ergün Cakal reviews the definition and prohibition of sleep deprivation as torture and ill-treatment in international law, and the potential contribution of medical and psychological knowledge to the development of greater nuance in legal standards. The review is part of an international cooperative study on sleep deprivation by the Danish Institute Against Torture (DIGNITY), the Public Committee Against Torture in Israel (PCATI) and REDRESS. The three organisations explain the process of elaboration of a protocol of exploration of SD and data with preliminary validation in Israel. The Protocol itself is also included in the section. Finally, Mahmud Sehwail and colleagues at the Ramallah-based Treatment and Rehabilitation Centre for Victims of Torture (TRC) present a study in which, for the first time, they document that sleep deprivation produced a number of impacts including severe suffering. At the same time, they show that conviction rates and sentence length were not increased as a result of admissions of guilt obtained from sleep-deprived detainees. In short, the paper suggests that sleep deprivation as torture is not only ethically questionable, but useless from the perspective of the interrogator.

This issue is complemented by an epidemiological study by Brenda Van Den Bergh and colleagues on knowledge, attitudes and practice about torture and torture practices among medical professionals in Tanzania. This expands early data published in our Journal in 2018 (Aon, Sungusia, Brasholt, Van Den Bergh \& Modvig, 2018).

Pearl Fernandes and Yvette Aiello from STARTTS-Australia expand their previous publication of group therapy with Tamil survivors of sexual violence in a case report that exemplifies the narratives of survivors and how are they addressed in therapy. 
Finally, we include a Debate. Efrat Shir presents a recent Israeli Supreme Court ruling - the case of Mr Firas Tbeish and the implications for the fight against torture in Israel. Hans Draminsky Petersen and John W. Schiemann-members of the Torture Journal Editorial Advisory Board-provide comment.

\section{References}

Åkerstedt, T., Ghilotti, F., Grotta, A., Bellavia, A., Lagerros, Y. T., \& Bellocco, R. (2017). Sleep duration, mortality and the influence of age. European fournal of Epidemiology, 32(10), 881891. https://doi.org/10.1007/s10654-017-0297-0

Baglioni, C., Nanovska, S., Regen, W., Spiegelhalder, K., Feige, B., Nissen, C., ... Riemann, D. (2016). Sleep and mental disorders: A meta-analysis of polysomnographic research. Psychological Bulletin, 142(9), 969-990. https://doi.org/10.1037/ bul0000053

Baldwin, J. (1993). OF Establishing Truth or Proof? The British fournal of Criminology, 33(June 1990), 66-72.

Barnes, C. M., Gunia, B. C., \& Wagner, D. T. (2015). Sleep and moral awareness. Fournal of Sleep Research, 24(2), 181-188. https://doi.org/10.1111/ jsr. 12231

Biderman, A., \& Zimmer, H. (1961). The Manipulation of Human Behaviour. New York: John Wiley and Sons.

Blagrove, M. (1996). Effects of Length of Sleep Deprivation on Interrogative Suggestibility. fournal of Experimental Psychology: Applied, 2(1), 48-59. https://doi.org/10.1037/1076-898X.2.1.48

Blagrove, M., \& Akehurst, L. (2000). Effects of sleep loss on confidence-accuracy relationships for reasoning and eyewitness memory. fournal of Experimental Psychology: Applied, 6(1), 59-73. https://doi.org/10.1037/1076-898X.6.1.59

Boland, E. M., Rao, H., Dinges, D. F., Smith, R. V., Goel, N., Detre, J. A., ... Gehrman, P. R. (2017). Meta-Analysis of the Antidepressant Effects of Acute Sleep Deprivation. The fournal of Clinical Psychiatry, 78(8), e1020-e1034. https://doi. org/10.4088/JCP.16r11332

Bolgiano, D. (2010). Military interrogation of terror suspects. Military Review, (December), 1-10.

Cappuccio, F. P., D'Elia, L., Strazzullo, P., \& Miller, M. A. (2010). Sleep duration and all-cause mortality: A systematic review and meta-analysis of prospective studies. Sleep, 33(5), 585-592. https://doi.org/10.1093/sleep/33.5.585
Chen, L., Qi, X., \& Zheng, J. (2018). Altered regional cortical brain activity in healthy subjects after sleep deprivation: A functional magnetic resonance imaging study. Frontiers in Neurology, 9(AUG), 1-7. https://doi.org/10.3389/ fneur.2018.00588

Dai, X.-J., Rao, H., \& Spiegelhalder, K. (2019). Neuroimaging Findings in Sleep Disorders and Circadian Disruption. Frontiers in Neurology and Frontiers in Psychiatry, 10(May). https://doi. org/10.3389/fneur.2019.00249

Davis, D., \& Leo, R. A. (2012). Interrogation-related regulatory decline: Ego depletion, failures of self-regulation, and the decision to confess. Psychology, Public Policy, and Law, 18(4), 673704. https://doi.org/10.1037/a0027367

Drizin, S., \& Leo, R. (2004). The problem of false confessions in the post- DNA world. North Carolina Law Review, 82, 891-1007.

Fairholme, C. P., \& Manber, R. (2015). Sleep, Emotions, and Emotion Regulation: An Overview. In Sleep and Affect:Assessment, Theory, and Clinical Implications. https://doi.org/10.1016/ B978-0-12-417188-6.00003-7

Feld, B. C. (2013). Real interrogation: What actually happens when cops question kids. Law and Society Review, 47(1), 1-35. https://doi. org/10.1111/lasr.12000

Feng, P., Becker, B., Zheng, Y., \& Feng, T. (2018). Sleep deprivation affects fear memory consolidation: Bi-stable amygdala connectivity with insula and ventromedial prefrontal cortex. Social Cognitive and Affective Neuroscience, 13(2), 145-155. https://doi.org/10.1093/scan/nsx 148

Frenda, S. J., Patihis, L., Loftus, E. F., Lewis, H. C., \& Fenn, K. M. (2014). Sleep Deprivation and False Memories. Psychological Science, 25(9), 1674-1681. https://doi. org/10.1177/0956797614534694

Goldstein-Piekarski, A. N., Greer, S. M., Saletin, J. M., \& Walker, M. P. (2015). Sleep deprivation impairs the human central and peripheral nervous system discrimination of social threat. Fournal of Neuroscience, 35(28), 10135-10145. https://doi.org/10.1523/ JNEUROSCI.5254-14.2015

Greenberg, I. (2015). From surveillance to torture: The evolution of US interrogation practices during the War on Terror. Security fournal, 28(2), 165-183. https://doi.org/10.1057/sj.2015.7

Gudjonsson, G. H. (2003). The psychology of interrogations and confessions. A handbook. London: Wiley.

Gudjonsson, G. H., Sigurdsson, J. F., Sigfusdottir, I. D., Asgeirsdottir, B. B., González, R. A., \& 
Young, S. (2016). A national epidemiological study investigating risk factors for police interrogation and false confession among juveniles and young persons. Social Psychiatry and Psychiatric Epidemiology, 51(3), 359-367. https:// doi.org/10.1007/s00127-015-1145-8

Havekes, R., \& Abel, T. (2017). The tired hippocampus: the molecular impact of sleep deprivation on hippocampal function. Current Opinion in Neurobiology, 44(March), 13-19. https://doi.org/10.1016/j.conb.2017.02.005

Hennecke, E., Elmenhorst, D., Mendolia, F., Putzke, M., Bauer, A., Aeschbach, D., \& Elmenhorst, E. M. (2019). Reestablishment of individual sleep structure during a single 14 -h recovery sleep episode after $58 \mathrm{~h}$ of wakefulness. Fournal of Sleep Research, 28(3). https://doi.org/10.1111/jsr.12641

Hertenstein, E., Feige, B., Gmeiner, T., Kienzler, C., Spiegelhalder, K., Johann, A., ... Baglioni, C. (2019). Insomnia as a predictor of mental disorders: A systematic review and meta-analysis. Sleep Medicine Reviews, 43, 96-105. https://doi. org/10.1016/j.smrv.2018.10.006

Hirshkowitz, M., Whiton, K., Albert, S. M., Alessi, C., Bruni, O., DonCarlos, L., ... Adams Hillard, P. J. (2015). National Sleep Foundation's sleep time duration recommendations: methodology and results summary. Sleep Health, 1(1), 40-43. https://doi.org/10.1016/j.sleh.2014.12.010

Horne, J. A., \& Pettitt, A. N. (1985). High incentive effects on vigilance performance during 72 hours of total sleep deprivation. Acta Psychologica, 58(2), 123-139. https://doi.org/10.1016/00016918(85)90003-4

Horne, J. a, \& Harrison, Y. (2000). The impact of sleep deprivation on decision making: a review. fournal of Experimental Psychology. Applied, 6(3), 236-249. https://doi.org/10.1037//1076898x.6.3.236

Hoyos, C., Glozier, N., \& Marshall, N. S. (2015). Recent Evidence on Worldwide Trends on Sleep Duration. Current Sleep Medicine Reports, 1(4), 195-204. https://doi.org/10.1007/s40675-0150024-x

Intelligence Science Board. (2009). Intelligence interviewing. Teaching papers and case studies. Washington DC: National Defense Intelligence College Press.

Kassin, S. M., Leo, R. A., Meissner, C. a, Richman, K. D., Colwell, L. H., Leach, A.-M., ... Fon, D. La. (2007). Police Interviewing and Interrogation: A Self-Report Survey of Police Practices and Beliefs. Law and Human Behavior, 31(4), 381-400. https://doi.org/10.1007/s10979006-9073-5
Killgore, W. D. S. (2010). Effects of sleep deprivation on cognition. In Progress in Brain Research (Vol. 185). https://doi.org/10.1016/B978-0-444-537027.00007-5

Killgore, W. D. S., Balkin, T. J., Yarnell, A. M., \& Capaldi, V. F. (2017). Sleep deprivation impairs recognition of specific emotions. Neurobiology of Sleep and Circadian Rhythms, 3(February), 10-16. https://doi.org/10.1016/j.nbscr.2017.01.001

Killgore, W. D. S., Killgore, D. B., Day, L. M., Li, C., Kamimori, G. H., \& Balkin, T. J. (2007). The effects of 53 hours of sleep deprivation on moral judgment. Sleep, 30(3), 345-352. https://doi. org/10.1093/sleep/30.3.345

Kong, D., Liu, R., Song, L., Zheng, J., Zhang, J., \& Chen, W. (2018). Altered long- and shortrange functional connectivity density in healthy subjects after sleep deprivations. Frontiers in Neurology, 9(JUL), 1-11. https://doi.org/10.3389/ fneur.2018.00546

Krizan, Z., \& Herlache, A. D. (2016). Sleep Disruption and Aggression: Implications for Violence and Its Prevention. Psychology of Violence, 6(4), 542-552. https://doi.org/10.1037/ vio0000018

Lautenbacher, S., Kundermann, B., \& Krieg, J. C. (2006). Sleep deprivation and pain perception. Sleep Medicine Reviews, 10(5), 357-369. https:// doi.org/10.1016/j.smrv.2005.08.001

Lim, J., \& Dinges, D. F. (2010). A meta-analysis of the impact of short-term sleep deprivation on cognitive variables. Psychological Bulletin, 136(3), 375-389. https://doi.org/10.1037/a0018883

Liu, X., Peng, X., Peng, P., Li, L., Lei, X., \& Yu, J. (2019). The age differences of sleep disruption on mood states and memory performance. Aging and Mental Health, $0(0), 1-8$. https://doi.org/10.1 080/13607863.2019.1603286

Madon, S., Yang, Y., Smalarz, L., Guyll, M., \& Scherr, K. C. (2013). How factors present during the immediate interrogation situation produce shortsighted confession decisions. Law and Human Behavior, 37(1), 60-74. https://doi.org/10.1037/ lhb0000011

McKenna, B. S., Dickinson, D. L., \& Orff, H. J. (2007). The effects of one night of sleep deprivation on known-risk and ambiguous-risk decisions. F Sleep Research, 16, 245-252.

Mendez, J. E. (2011). Interim report of $S R$ on torture (solitary confinement) $A / 66 / 268$. 44570(August).

Mikulincer, M., Babkoff, H., Caspy, T., \& Sing, H. (1989). The effects of 72 hours of sleep loss on psychological variables. British fournal of Psychology, 80(2), 145-162. https://doi. org/10.1111/j.2044-8295.1989.tb02309.x 
Morgan, R., \& Evans, M. (2001). CPT Standards regarding Prisoners. Geneva: Association for The Prevention of Torture.

Ohayon, M. M., Carskadon, M. A., Guilleminault, C., \& Vitiello, M. V. (2004). Meta-analysis of quantitative sleep parameters from childhood to old age in healthy individuals: developing normative sleep values across the human lifespan. Sleep, 27(7), 1255-1273. Retrieved from http:// www.ncbi.nlm.nih.gov/pubmed/15586779

Pereira, T., Martins, S., \& Fernandes, L. (2017). Sleep duration and suicidal behavior: A systematic review. European Psychiatry, 41, S854. https://doi.org/10.1016/j.eurpsy.2017.01.1699

Pérez-Sales, P. (2017). Psychological torture: Definition, evaluation and measurement. In Psychological Torture: Definition, Evaluation and Measurement. https://doi. org/10.4324/9781315616940

Reynolds, A. C., \& Banks, S. (2010). Total sleep deprivation, chronic sleep restriction and sleep disruption. In Progress in Brain Research (Vol. 185). https://doi.org/10.1016/B978-0-444-537027.00006-3

Schnyer, D. M., Zeithamova, D., \& Williams, V. (2009). Decision-making under conditions of sleep deprivation: Cognitive and neural consequences. Military Psychology, 21(SUPPL. 1). https://doi.org/10.1080/08995600802554607

Schrimpf, M., Liegl, G., Boeckle, M., Leitner, A., Geisler, P., \& Pieh, C. (2015). The effect of sleep deprivation on pain perception in healthy subjects: A meta-analysis. Sleep Medicine, 16(11), 1313-1320. https://doi.org/10.1016/j. sleep. 2015.07.022

Simonelli, G., Marshall, N. S., Grillakis, A., Miller, C. B., Hoyos, C. M., \& Glozier, N. (2018). Sleep health epidemiology in low and middle-income countries: a systematic review and meta-analysis of the prevalence of poor sleep quality and sleep duration. Sleep Health, 4(3), 239-250. https://doi. org/10.1016/j.sleh.2018.03.001

Sveaass, N. (2008). Destroying Minds: Psychological Pain and the Crime of Torture. CUNY Law Review, 11(2), 303. https://doi.org/10.31641/ $\operatorname{clr} 110210$

Tempesta, D., Couyoumdjian, A., Curcio, G., Moroni, F., Marzano, C., De Gennaro, L., \& Ferrara, M. (2010). Lack of sleep affects the evaluation of emotional stimuli. Brain Research Bulletin, 82(1-2), 104-108. https://doi. org/10.1016/j.brainresbull.2010.01.014

Tempesta, D., Couyoumdjian, A., Moroni, F., Marzano, C., De Gennaro, L., \& Ferrara, M. (2012). The impact of one night of sleep deprivation on moral judgments. Social

Neuroscience, 7(3), 292-300. https://doi.org/10.10 80/17470919.2011.614002

Trivedi, M. S., Holger, D., Bui, A. T., Craddock, T. J. A., \& Tartar, J. L. (2017). Short-term sleep deprivation leads to decreased systemic redox metabolites and altered epigenetic status. PLoS ONE, 12(7), 1-13. https://doi.org/10.1371/ journal.pone.0181978

US Army. (2006). FM 2-22.3. Human Intelligence Collector Operations. (Vol. 3). Washington DC.

Watson, N. F., Badr, M. S., Belenk, G., \& Bliwise, D. L. (2015). Recommended amount of sleep for a healthy adult. American Academy of Sleep Medicine and Sleep Research Society, 38(6), 843-844. https://doi.org/10.5665/sleep.4716

Yetish, G., Kaplan, H., Gurven, M., Wood, B., Pontzer, H., Manger, P. R., ... Siegel, J. M. (2015). Natural sleep and its seasonal variations in three pre-industrial societies. Current Biology, 25(21), 2862-2868. https://doi.org/10.1016/j. cub.2015.09.046

Yin, J., Jin, X., Shan, Z., Li, S., Huang, H., Li, P., ... Liu, L. (2017). Relationship of sleep duration with all-cause mortality and cardiovascular events: A systematic review and dose-response meta-analysis of prospective cohort studies. Fournal of the American Heart Association, 6(9). https://doi.org/10.1161/JAHA.117.005947 